\title{
Mapping the world of complex concentrated alloys
}

\author{
Stéphane Gorsse ${ }^{1,2,3}$, Daniel B. Miracle ${ }^{4}$, Oleg N. Senkov ${ }^{4}$ \\ ${ }^{1}$ CNRS, Univ. Bordeaux, ICMCB, UPR 9048, F-33600 Pessac, France \\ ${ }^{2}$ Bordeaux INP, ENSCBP, F-33600 Pessac, France \\ ${ }^{3}$ Wright State University, Dayton, $\mathrm{OH}, \mathrm{USA}$ \\ ${ }^{4}$ Air Force Research Laboratory, Materials and Manufacturing Directorate, Wright-Patterson AFB, Ohio \\ 45433, USA
}

\section{ABSTRACT}

This work explores the mechanical properties of high entropy alloys (HEAs) and complex concentrated alloys (CCAs) by comparing them with commercially available engineering alloys including industrystandard aerospace alloys. To reach this goal we have developed a materials database covering the main mechanical properties of HEAs and CCAs from the published literature. The database is used to represent various property spaces enabling an assessment of their performance for light weight structures and high-temperature structural applications. In addition, we illustrate the effects of alloying and of specific elements on the room temperature mechanical properties of HEAs and CCAs. With densities between titanium alloys and steels or nickel alloys, the best CCAs exceed commercial alloys in uniaxial loading and beam bending at room temperature. Where use temperature or cost excludes commercial alloys based on $\mathrm{Mg}$, $\mathrm{Al}$ or $\mathrm{Ti}$, the best CCAs also offer attractive specific yield strength in panel bending and specific stiffness for all loading conditions at room temperature. Many CCAs have superior structural properties at elevated temperatures. 


\section{KEYWORDS}

High entropy alloys, complex concentrated alloys, mechanical properties, materials selection, property space.

\section{INTRODUCTION}

This article aims to represent in a visual, concise and explicit way what is experimentally known about the mechanical properties of high entropy alloys (HEAs) and related alloying concepts (multi-principle element alloys - MPEAs, complex concentrated alloys - CCAs). HEAs represent a new branch of the metallic alloy tree, first published in 2004 [1-3]. The distinguishing feature of these alloying concepts is that they contain several major elements without a clear base element in contrast with conventional metallic alloys that have one major element and several minor additions of alloying elements (Figure 1). The basic concept behind the design of HEAs is to promote the formation of single-phase-disordered solid solutions stabilized by configurational entropy. For an ideal mixture, the configurational entropy increases with the number of constituent species and with element concentration approaching equiatomic composition, and the maximum is achieved at the equiatomic composition. In that case, the entropic contribution to the total Gibbs energy is enhanced, improving the stability of disordered solid solutions relative to intermetallic phases, especially at high temperatures where the energy landscape is dominated by entropy (Figure 1).

Mechanical properties of single-phase, solid solution HEAs are controlled by three classical strengthening mechanisms: solid solution hardening, work-hardening and grain size (Hall-Petch) hardening. These strengthening mechanisms become less effective above about half the absolute melting temperature due to recovery, recrystallization, grain growth and diffusive drag of solute atoms. However, the HEA field has evolved quickly and is no longer restricted to single-phase, solid solution microstructures. According to a recent review encompassing 648 combinations of alloy compositions and thermo- 
mechanical treatments, 435 reports show microstructures with 2 or more phases [4]. Observed phases include disordered solid solutions, amorphous phases and intermetallic compounds. A large variety of morphologies are seen, arising from phase transformations that include order/disorder transformation $[5,6]$, spinodal decomposition [7-10], precipitation $[4,11,12]$ and massive transformation $[13,14]$. Multi-principal element alloys (MPEAs), which are also called complex concentrated alloys (CCAs), specifically include this microstructural complexity associated with multi-phase alloys in the central regions of multi-dimensional phase diagrams. It is not clear yet how both compositional and microstructural complexity influences CCA properties, or if they exhibit better properties than conventional alloys. Current comparisons evaluate HEA properties against a small number of conventional alloys that usually represent only one or two commercial alloy systems. Such comparisons may miss broader trends that may be apparent by comparing HEAs against the full range of structural metal alloys.

The purpose of this paper is to explore the world of CCAs, which also include HEAs, by comparing their mechanical properties against a broader range of commercial structural alloys. We illustrate the effect of alloy composition (alloy family, number of components, phases and effect of $\mathrm{Al}, \mathrm{Cr}$ and $\mathrm{Cu}$ ) on mechanical properties using a dedicated database and property charts that summarize key findings and show trends and profiles. This database reflects the state of the art of the field of HEAs and CCAs by using published mechanical properties data [4, 15-70]. The majority of published CCA studies provide only hardness and compression data of as-cast alloys, and a growing number gives tensile properties of thermomechanically processed alloys. The database contains a total of 325 CCA alloys with properties that are not equally populated for every alloy due to the lack of literature data:

- Density (325/325 alloys, experimentally measured or estimated using the rule of mixtures: $\rho=$ $\sum c_{i} M_{i} / \sum c_{i} V_{i}$ where $c_{i}, M_{i}$ and $V_{i}$ are the atomic fraction, molar mass and molar volume of the element $i$ ). 
- Hardness (208/325)

- $\quad$ Room temperature yield strength (130/325, of which 37 are from tensile tests)

- Yield strength (temperature dependent, 18/325)

- Ultimate strength (68/325, of which 37 are from tensile tests)

- Ductility (125/325, of which 37 are elongations from tensile tests)

- Young's modulus (273/325, experimentally measured or estimated using the rule of mixtures).

CES software [71] was used to browse the database and to plot properties or combinations of properties and to select constraints to screen and rank materials behavior.

The reported results are divided into two sections. In the first one we show a panoramic view of the world of CCAs, and illustrate how they compare with commercial structural alloys. In the second part, we explore a closer view of the effects of composition on mechanical properties. We rely on the notion of material-property spaces and materials indices as defined by M. Ashby [72].

\section{RESULTS AND DISCUSSION}

\section{CCAs: A Bird Eyes}

\subsection{Materials network}

To organize the world of CCAs into families, we represent 110 alloy compositions reported in the literature as a network (Figure 2). As a social network analysis maps relationships between people, this alloy network analysis (ANA) visually shows relationships between the alloys. Each node is a unique alloy, and a line linking two nodes indicates the sharing of at least one common element. The strength of a link is proportional to the number of elements shared between two nodes. Modularity [73] detects alloy families, defined as groups of densely interconnected nodes (alloys) that share many common elements and have sparser connections with the rest of the network. The spatialization of nodes is obtained using the ForceAtlas2 algorithm implemented in the Gephi software [74], in which nodes repulse each other 
while links act as springs attracting the nodes they connect. Figure $\mathbf{2}$ shows that CCAs cluster in five different families denoted by colored bubbles: $3 \mathrm{~d}$ transitions metal CCAs, refractory metal CCAs, light metal CCAs, CCA brasses and bronzes, and $4 f$ transition metal (lanthanide) CCAs. These are the same alloy families identified earlier by a more subjective analysis [4]. CCAs containing $\mathrm{B}, \mathrm{C}, \mathrm{N}$ or $\mathrm{O}$ are not included in this evaluation, nor are CCAs based on precious metals. 3d transition metal CCAs share four common elements with refractory metal CCAs ( $\mathrm{Al}, \mathrm{Ti}, \mathrm{V}, \mathrm{Cr}$ ) and with CCA brasses and bronzes ( $\mathrm{Al}, \mathrm{Mn}$, $\mathrm{Ni}, \mathrm{Cu}$ ), and so these families overlap in Figure 2. It can also be seen that CCA brasses and bronzes can be considered as a small sub-family of $3 \mathrm{~d}$ transition metal CCAs that contain the additional elements of $\mathrm{Sn}$ and $\mathrm{Zn}$. Other pairs of families share fewer elements and so their bubbles in Figure $\mathbf{2}$ do not overlap, but links are present showing some connection between these pairs of families. In the extreme, the $4 f$ transition metal alloy family (lanthanides) shares no elements with any of the other four alloy families, so the $4 \mathrm{f}$ family bubble is totally isolated from the others (no overlap and no links).

Based on this network analysis, we have developed a material database with a tree-like structure. The universe of CCAs contains the 5 families found from the ANA, plus ceramic CCAs (oxides, borides, carbides, and nitrides). Each family encompasses two or more classes, each characterized by a unique formula (e.g. Al ${ }_{x} \mathrm{CoCrFeNi}$ ), and each class encloses members having the same elements but with different proportions. Each member (alloy) is characterized by a set of properties and a listing of these properties makes up a record for that material. The database contains a total of 325 alloys with their mechanical and physical properties.

\subsection{How do CCAs fill the gaps in room-temperature material-property spaces?}

Here we display a series of charts to compare CCAs with commercial structural alloys (Mg-, Al-, Ti-, Feand Ni-based alloys and refractory alloys) to illustrate how they compete for structural applications. Figure 3 shows the materials property space where the room temperature yield strength is plotted 
against density using logarithmic scales. Individual alloys (shown as open and closed circles) are enclosed in large bubbles that represent alloy families. The $3 \mathrm{~d}$ transition metal family of CCAs is shown by tealcolored bubbles, refractory metal CCAs are shown by yellow bubbles and light metal CCAs are shown by orange bubbles. Individual classes of alloys within these two alloy families are also shown with small circles (see Fig. 5). Each family occupies a particular area of property space. The dashed lines are guidelines for materials selection, and represent the performance index for three different loading conditions: uniaxial loading (slope, $\mathrm{s}=1$, corresponding to the material index $\sigma_{Y} / \rho$ where $\sigma_{Y}$ and $\rho$ are the yield strength and the density, respectively); beam bending ( $s=3 / 2$ for $\sigma_{Y}^{2 / 3} / \rho$ ); and panel bending ( $\mathrm{s}=2$ for $\left.\sigma_{Y}^{1 / 2} / \rho\right)$ [72]. Materials above a performance index line have higher values of that performance index than those below it, so that lighter and stronger structures can be made from alloys above the line. The relative merits of the new alloys being evaluated depend not only on the properties of each alloy but also on the loading conditions, so that comparing materials classes with different performance index lines can give different results. Each line in Figure $\mathbf{3}$ is positioned vertically until it contacts the uppermost part of the last commercial alloy family bubble, so that essentially all of the data are below each line. In this way, the best alloys for a given performance index can be easily illustrated: at room temperature, steel is the best among other conventional alloy families for uniaxial tension whereas magnesium alloys are the best commercial alloys for beam and panel bending. The three performance indices considered here cover the full range of responses (from shallowest to steepest performance index lines) for a broader range of loading conditions [72].

$3 \mathrm{~d}$ transition metal and refractory metal CCAs overlap with steels and $\mathrm{Ni}$ alloys in room temperature yield strength - density space, especially below the yield strength, $\sigma_{\gamma}$, of about $2000 \mathrm{MPa}$. However, both $3 \mathrm{~d}$ transition metal and refractory metal CCAs also begin to fill the gap between steels and Ti alloys, offering new materials design options. In terms of the specific yield strength performance index, the room temperature properties of $3 \mathrm{~d}$ transition metal CCAs are marginally better than the best steels in 
uniaxial loading $(s=1)$, and so are better than any of the conventional alloys. $3 d$ transition metal CCAs are also essentially equivalent to the best $\mathrm{Mg}$ alloys in beam bending $(\mathrm{s}=3 / 2)$. Panel bending $(\mathrm{s}=2)$ places a premium on low density, and so conventional alloys based on $\mathrm{Mg}, \mathrm{Al}$ and $\mathrm{Ti}$ all significantly outperform $3 \mathrm{~d}$ transition metal and refractory CCAs in this loading condition. Thus, the currently available $3 \mathrm{~d}$ transition metal CCAs do not compete with commercial alloys in panel bending specific strength at room temperature. However, room temperature specific properties are only one design criterion, in many cases alloys must also perform at elevated temperatures and must meet stringent cost requirements. In applications where the maximum use temperature may eliminate alloys based on $\mathrm{Al}$ and $\mathrm{Mg}$, and where cost requirements may remove Ti alloys from consideration, the $3 \mathrm{~d}$ transition metal CCAs emerge as an attractive new class of materials that may compete with conventional steels and nickel alloys. Of course, to successfully compete, the $3 d$ transition metal CCAs must be further characterized and developed to possess all properties required for structural materials, including fracture-resistant properties such as tensile ductility and mode I fracture toughness. These properties need to be characterized in the $3 d$ transition metal CCAs with the highest values of room temperature specific yield strength to further evaluate their potential as an attractive option for structural materials. Refractory metal CCAs do not compete with the best commercial alloys for any of the three room temperature loading conditions considered here. Their response at elevated temperatures is considered in Section 1.3. However, most of refractory metal CCAs outperform conventional refractory alloys by all three performance indexes. Moreover, almost all of them have considerably lower density, than conventional refractory alloys, which is comparable with the density of steels and Ni alloys, as well as $3 \mathrm{~d}$ transition metal CCAs.

Light metal CCAs span the gap between conventional Al and Ti alloys. This mimics a major feature displayed by $3 d$ transition metal and refractory metal CCAs, which fill the specific properties gap between conventional steels, titanium alloys and nickel alloys. Alkaline earth and alkali metals give the 
nine lowest density metallic elements, however they are either toxic $(\mathrm{Be})$ or extremely reactive. Of these, only $\mathrm{Mg}$ is suitable as an alloy base element, since it is not toxic and it forms a passivating layer that allows it to resist catastrophic reaction with air and water. The next lowest density metal is aluminum, which is also a common alloy base element. The issues of reactivity and toxicity limit the number of light metal elements suitable for structural alloys, and so light metal CCAs have densities that are higher than aluminum alloys. However, alloying extremely reactive metals such as $\mathrm{Ca}$, even with other reactive metals such as $\mathrm{Mg}, \mathrm{Zn}$ and $\mathrm{Al}$, can significantly reduce catastrophic environmental attack and can even produce alloys with protective oxide reaction products [75]. Thus, alkaline earth and alkali metal elements may still show potential as principal alloy elements in light metal CCAs.

Comparison of room temperature Young's modulus - density space is shown in Figure 4a. In this material property space, CCAs more clearly fill the space between steels and Ti alloys. The very best $3 \mathrm{~d}$ transition metal CCA is nominally equivalent to the best commercial alloys (Al alloys, steels, Ni alloys, refractory alloys), but is significantly poorer than the best commercial structural alloys in beam and panel bending, especially Mg-based, Al-based and Ti-based alloys. As for specific Young's modulus, $3 \mathrm{~d}$ transition metal CCAs are better than conventional alloys when application temperature and cost may eliminate $\mathrm{Mg}, \mathrm{Al}$ and Ti based alloys. Again, refractory metal CCAs do not compete with the best commercial alloys in specific stiffness at room temperature.

Figure $\mathbf{4 b}$ shows room temperature yield strength and Young's modulus. The shading on the bottom left shows the theoretical strength $\left(\sigma_{y}=E / 20\right)$ delimiting the boundary of the inaccessible region of the plot. CCAs lie in the broad range populated by conventional alloys. However, RCCAs are located at the upper edge, approaching more closely the theoretical strength limit than other CCAs and conventional alloys.

Here we give a more detailed comparison of 3d transition metal CCAs with competing commercial alloys. From Figure 3, a small number of 3d transition metal CCAs are slightly better than the best steels when considering specific yield strength in uniaxial loading, and a larger number of $3 \mathrm{~d}$ transition metal CCAs 
out-compete the best steels in beam and panel bending. The specific alloy classes of the $3 \mathrm{~d}$ transition metal CCAs are shown in detail in Figure 5a. Steels with $\sigma_{Y} \geq 2000 \mathrm{MPa}$ are typically maraging steels. These are highly alloyed Fe-Ni-Co-Mo alloys. In addition to very high strengths, these alloys also have tensile elongations $\geq 6 \%$, fracture toughness values greater than $30 \mathrm{MPa} \mathrm{m}^{1 / 2}$ and Charpy $\mathrm{V}$-notch impact energies greater than $20 \mathrm{~J}$. The fatigue properties and stress corrosion cracking resistance of maraging steels are much better than other ultra-high strength steels. Further, maraging steels can be hot-worked and cold-worked by conventional techniques, they can be machined by all conventional methods when in the solution-annealed or age-hardened condition, and can be joined using all conventional welding methods. However, maraging steels are much more expensive than standard steels and their availability is limited due to extra care in processing that is needed to keep impurities such as $\mathrm{C}, \mathrm{Mn}, \mathrm{S}$ and $\mathrm{P}$ to a minimum. These alloys must also be heat treated to produce the desired properties. To successfully compete with maraging steels at room temperature, candidate $3 \mathrm{~d}$ transition metal CCAs must be developed with a similar balance of mechanical properties. In addition to specific yield strength considered here, other properties such as tensile ductility, Mode I fracture toughness, fatigue and impact resistance must also be demonstrated. Further, the ability to melt, form, machine and join candidate CCAs needs to be established. Finally, cost and availability are major factors that need to be considered. Comparisons between $3 \mathrm{~d}$ transition metal CCAs, stainless steels and commercial Ni alloys is suggested by the common elements in these alloy families. Commercial stainless steels all have $\mathrm{Fe}, \mathrm{Cr}$ and $\mathrm{Ni}$ as major elements. Other elements often used at low levels (typically $<5$ wt. \%) in stainless steels include $\mathrm{Al}, \mathrm{Cu}$, $\mathrm{Nb}$ and $\mathrm{Ti}$ (for precipitation hardening); $\mathrm{Nb}$, Ta and $\mathrm{Ti}$ (for reduced sensitization); Mo (for pitting resistance); and $\mathrm{Mn}$ and $\mathrm{N}$ (for improved strength). Stainless steels also typically have controlled amounts of C (0.03 to 1.0 wt. \%) and Si (0.5 to 4.5 wt. \%). Ni-alloys often have Co (0-45 wt. \%), Cr (20-80 wt. \%), $\mathrm{Cu}(0-25$ wt. \%), $\mathrm{Fe}(0-60$ wt. \%) and/or Mo (0-30 wt. \%) as major constituents and lower levels of $\mathrm{Al}, \mathrm{Mn}, \mathrm{Nb}, \mathrm{Si}, \mathrm{Ti}$ and/or $\mathrm{V}$. By comparison, the 3d transition metal CCAs with the highest specific yield 
strengths all have $\mathrm{Cr}$, $\mathrm{Fe}$ and $\mathrm{Ni}$ as major elements, all but one have $\mathrm{Al}$, and all but one have Co (Figure $\mathbf{5 b}, \mathbf{c})$. Other elements used infrequently include $\mathrm{C}, \mathrm{Cu}, \mathrm{Nb}, \mathrm{Mn}, \mathrm{Mo}, \mathrm{Si}, \mathrm{Ti}$ or $\mathrm{V}$. Stated differently, CCAs exhibiting the best specific yield strengths belong to the AlCoCrFeNi(X) class of alloys, with $X=C, C u, N b$, $\mathrm{Mn}, \mathrm{Mo}, \mathrm{Si}, \mathrm{Ti}$ or $\mathrm{V}$ ( $\mathrm{Al}$ is absent in one of these alloy classes, and $\mathrm{Co}$ is absent in another). The elemental overlap between $3 \mathrm{~d}$ transition metal CCAs and stainless steels or Ni alloys is remarkable.

A performance index line for uniaxial loading (slope, $s=1$ ) is shown in Figure $\mathbf{5 b , c}$. Nearly two dozen $\mathbf{3 d}$ transition metal CCAs have better room temperature specific yield strength in uniaxial loading relative to stainless steels (Figure 5b) and nearly three dozen exceed commercial $\mathrm{Ni}$ alloys (Figure 5c). Even more $\mathbf{3 d}$ transition metal CCAs out-compete stainless steels or Ni alloys in beam or plate bending. In some cases, the potential improvements are significant. However, the specific yield strengths in all of the $3 d$ transition metal CCAs above the $s=1$ performance index in these comparisons are derived from hardness values or are obtained from compressive loading. A recent comparison of stainless steels and $3 d$ transition metal CCAs tested in tension concluded that these two families are essentially equivalent in tensile yield strength, ultimate tensile strength and tensile ductility as a function of temperature [4]. Density was not considered in this earlier assessment.

These high CCA specific yield strengths can be related to their microstructures. A recent CCA review gives 18 different alloy microstructure reports from 15 different sources for equiatomic AlCoCrFeNi (see [4], Supplementary Information). The as-cast microstructure is most often reported to be BCC (6 reports) or $\mathrm{BCC}+\mathrm{B} 2$ (5 reports), but is also reported to be $\mathrm{B} 2$ (3 reports), $\mathrm{FCC}+\mathrm{B} 2$ (1 report) or $\mathrm{L}_{2}+\mathrm{B} 2$ (1 report). Here, intermetallic compounds (IM) are labeled using Strukturbericht notation - the B2 structure has the cP2 Pearson symbol (prototype $\mathrm{CsCl}$ ) and in the present alloys is most likely associated with the NiAl phase. The $\mathrm{L}_{2}$ structure is given as $\mathrm{CP} 4\left(\mathrm{AuCu}_{3}\right)$ and is typically associated with $\mathrm{Ni}_{3} \mathrm{Al}$. Given the difficulty in identifying IM phases using X-ray diffraction alone [4], it is likely that the B2 phase is a major microstructural constituent in AlCoCrFeNi. Only two studies characterize AlCoCrFeNi in the annealed 
condition, and both report an FCC+B2 microstructure. The addition of Mo to AlCoCrFeNi introduces the $\sigma$ phase (D8 $\left.8_{b}, \mathrm{tP} 30, \sigma-\mathrm{CrFe}\right), \mathrm{Nb}$ produces the hexagonal Laves phase $(\mathrm{C} 14, \mathrm{hP1}, \mathrm{MgZn} 2)$, Si produces an unidentified IM, and Ti produces $\mathrm{NiTi}_{2}$ (cF96). Equimolar AlCrFeMoNi has a B2+ $\sigma$ microstructure. See [4] for additional details regarding the microstructural assessment of these alloys. Thus, the CCAs that outcompete steels, stainless steels and $\mathrm{Ni}$ alloys in specific yield strength at room temperature have microstructures that are likely to contain significant volume fractions of one or more IM phases. By comparison, the commercial alloys considered here have no IM phases (with the exception of pearlitic steels, which have the metastable ceramic, $\mathrm{Fe}_{3} \mathrm{C}$, as a major microstructural constituent), or have them only as a minor microstructural constituent. Further, these CCA microstructures are likely to be in an unstable condition, as shown by the transformation to FCC+B2 upon annealing.

The high concentrations of alloy elements in CCAs are likely to produce these important microstructural differences. $\mathrm{Al}, \mathrm{Nb}, \mathrm{Si}$ and $\mathrm{Ti}$ are minor additions in the commercial alloys considered here, usually $<2$ wt.\% each, almost never $>5$ wt.\% each, and the total of Al+Ti is $<8$ wt.\% except for 2 alloys. However, in the CCAs considered here these elements have much higher concentrations (Al up to $14 \mathrm{wt} \%$, Nb up to 27 wt.\%, Si up to 10 wt.\% and Ti up to 16 wt.\%). The fracture-related properties (tensile ductility, fracture toughness, Charpy impact) have not been widely measured for these CCAs. Microstructures with significant IM constituents typically have poor fracture properties, especially for the IM phases found in the $\mathrm{AlCoCrFeNi}(\mathrm{X})$ class of alloys, and so it's tempting to assume that the CCAs considered here will have poor fracture properties. However, the size, morphology, distribution and volume fraction of the IM phase has a profound influence on fracture properties, and very few CCA studies have attempted to control these features. It is also possible that the compositional complexity of IM phases in CCAs may produce ductile IM phases. Binary B2 phases often deform by $<100>$ dislocations and thus have only 3 independent slip systems [76]. However, some B2 phases, such as FeAl, deform by <111> slip [77] and can provide the 5 independent slip systems needed for good fracture properties. CCAs have more 
elements than the B2 structure has sublattices, and so significant chemical mixing on B2 sub-lattices is likely to occur in $\mathrm{AlCoCrFeNi}(\mathrm{X}) \mathrm{CCAs}$. It is possible that this elemental mixing may alter the intrinsic slip behavior of the B2 phase. Careful deformation studies of the B2 phase in CCAs have not been reported, but are recommended for future studies.

Figure $5 d$ shows the room-temperature specific yield strength as a function of Young's modulus for different commercial alloys and CCAs. The Young's modulus of light metal CCAs is higher than that of Mg alloys, but it does not exceeds the Young's modulus of Al alloys. The specific strength of the current light metal CCAs is similar to that of the strongest Al and Mg alloys. Many currently reported 3d TM CCAs have the same Young's modulus range but much higher specific strength values than $\mathrm{Ni}$-based commercial alloys. The specific yield strength of 3d TM CCAs, which Young's modulus is below $200-250 \mathrm{GPa}$, is also noticeably higher than that of steels with similar Young's modulus. However, no 3d TM CCAs have yet been reported with $\mathrm{E}>250 \mathrm{GPa}$. Figure $5 \mathrm{~d}$ also uncover attractive combination of the properties of currently reported refractory metal CCAs. Namely, almost all these CCAs have the specific strength values, which are noticeably higher than those for commercial refractory alloys. By the specific strength, at similar or better Young's modulus values, RCCAs can compete with Ti alloys, Ni alloys, and even steels (at $\mathrm{E}<\sim 170 \mathrm{GPa}$ ). This analysis clear illustrates that the CCAs concept opens up possibility for discovering new alloy families with considerably improved combinations of the room temperature properties relative to the conventional commercial alloys.

\subsection{Material-property space for high temperature CCAs}

The temperature dependence of $\sigma_{Y}$ has been evaluated in the literature for some CCAs. The results are compiled in a modified yield strength - density plot (Figures 6a,b). Each alloy member is shown by a vertical bar at the appropriate density for that alloy. The height of each bar shows the range in yield strength for that alloy, and individual data points within a bar show the yield strengths measured at 
different temperatures. Not all alloys are characterized at the same temperatures, and so a direct comparison between alloys can be difficult. To solve this, we draw a line connecting the yield strengths for each CCA at $800^{\circ} \mathrm{C}$ (Figure 6a) and at $1000^{\circ} \mathrm{C}$ (Figure 6b). Ni alloys (including precipitation-hardened superalloys) at $800^{\circ} \mathrm{C}$ are superimposed on Figure $6 \mathbf{a}$, and a performance index line shows the highest value of specific yield strength for $\mathrm{Ni}$ alloys. CCAs above this performance index line exhibit higher specific yield strength at $800^{\circ} \mathrm{C}$ than the best Ni alloys at the same temperature. Figure $6 \mathbf{b}$ shows the same property space at $1000^{\circ} \mathrm{C}$ and Figure $6 \mathrm{c}$ shows only CCAs for which the yield strength at $1000^{\circ} \mathrm{C}$ was reported. As expected, $\sigma_{\mathrm{Y}}$ decreases with increasing temperature. At $800^{\circ} \mathrm{C}$, almost half of the refractory CCAs have higher performance indexes than $\mathrm{Ni}$ alloys. At $1000^{\circ} \mathrm{C}$, even more CCAs outperform commercial $\mathrm{Ni}$ alloys. These charts show the potential of refractory metal CCAs for high temperature application where high strength-to-density ratios (i.e. high specific strength) are required. In addition to tensile ductility, comparisons of oxidation and creep resistance are needed to better evaluate the potential of these CCAs toward high temperature applications. Comparing the fraction of the absolute melting temperature was not pursued in this work, since the melting temperature is known only for a small number of the CCAs in Figure 6. While the melting temperature can be calculated, the expected errors in the predicted melting temperatures are too large to make this comparison useful.

\section{Composition-properties}

\subsection{Effect of the number of elements}

Here we evaluate the effect of alloying on the room temperature specific yield strength of conventional alloys (Fig. 7a) and CCAs (Fig. 7b). Conventional alloying is broadly characterized by relatively small concentrations of alloying elements, such that the base metal dominates in all alloys. For example, in Fig. 7a Fe alloys (commercial purity iron, microalloyed and high strength steels, low and medium steels, and carbon steels) have at least 80 at.\% of the base element, $\mathrm{Mg}$ alloys have at least 85 at.\% of the base 
metal, Al alloys have a minimum of 80 at.\% for Al and titanium alloys are at least 90 at.\% Ti. However, the number of alloying elements in Fig. 7a covers a broad range, and varies from 0 to 7 . Low alloying concentrations can have a potent strengthening effect by using all classical strengthening mechanisms (solid solution hardening, grain refinement, work-hardening and precipitation-strengthening). However, only marginal density changes are expected based on the relatively low alloying concentrations. Thus, conventional alloying of common base elements significantly increases the room temperature yield strength but barely changes the alloy density, giving vertical trajectories in specific yield strength starting from the base elements. This trend is not surprising, since conventional alloys have been developed to increase the strength as much as possible with as little alloying addition as necessary. Further, low density is desired for many applications, especially for alloys based on $\mathrm{Al}, \mathrm{Mg}$ and $\mathrm{Ti}$, so low density elemental additions are more likely to be used in commercial alloys than high density elements that give similar strength increases.

This contrasts with CCA alloy trends (Fig. 7b). Here, the alloy strategy is defined by the combination of $N$ principle elements that, by definition, each have significant concentrations. The alloy density is thus likely to trend toward average values $[78,79]$. Fig. $7 \mathbf{b}$ shows that the density range is largest for the pure metallic elements $(N=1)$ from $\mathrm{Li}\left(534 \mathrm{~kg} / \mathrm{m}^{3}\right)$ to $\mathrm{W}\left(1930 \mathrm{~kg} / \mathrm{m}^{3}\right)$, and continually decreases as $N$ increases. The density limits also show a systematic averaging trend, so that the minimum and maximum densities for $N=6+$ are contained within the minimum and maximum densities for $N=4-5$, which are contained within the $N=2-3$ dataset (from 1770 to $20100 \mathrm{~kg} / \mathrm{m}^{3}$ for the commercial alloys Mg-12Li and W-50Re, respectively), which are contained within $N=1$. The overall density for each dataset trends toward higher values as $N$ increases, but always remains within the range exhibited by the pure elements. There is no significant difference in the mid-point densities for the $N=4-5$ and $N=6+$ datasets. These bubbles are centered on a density near $7,700 \mathrm{~kg} \mathrm{~m}^{-3}\left(7.7 \mathrm{~g} / \mathrm{cm}^{3}\right)$, which is the average density of all metallic elements excluding noble metals and actinides that are not included in this dataset. 
It's more difficult to anticipate trends for yield strength as a function of $N$. As with density, Fig. $7 \mathbf{b}$ shows that the range in room temperature yield strengths decreases and the center of gravity of each bubble increases with increasing $N$. However, the maximum yield strength increases with increasing $N$, while the maximum density decreases with increasing $N$. In fact, CCAs with $N=2-3$ have specific room temperature yield strengths higher than any pure element with equivalent density, CCAs with $N=4-5$ have specific yield strengths higher than any with $N=2-3$ at equivalent density, and alloys with $N=6+$ principle elements have specific yield strengths higher than any alloy with $N<6$ at the same density. This trend reflects the non-additive nature of strengthening.

\subsection{Effect of given elements $(\mathrm{Al}, \mathrm{Cu}, \mathrm{Cr}$...) in different structural property spaces and phases.}

The effect of Al on the properties and underlying phases of the analyzed CCAs show clear trends. Adding Al decreases density and can increase the room temperature yield strength (Fig. 8a). Al additions progressively transform austenitic microstructures of 3d TM CCAs to duplex (fcc+bcc) and to bcc+IM alloys (Fig. 8b). Microstructures listed as bcc may also contain the B2 intermetallic phase. These trends have recently been discussed in more detail [4].

Figure 9 illustrates graphically the influence of principal element additions on the room temperature specific yield strength (Fig. 9a) and yield strength vs. tensile ductility (Fig. 9b). Using Ni as an arbitrary starting point in the lower-right corner of Fig. 9a, sequential additions of $\mathrm{Co}, \mathrm{Fe}, \mathrm{Co}+\mathrm{Fe}, \mathrm{Co}+\mathrm{Fe}+\mathrm{Mn}$, $\mathrm{Co}+\mathrm{Mn}, \mathrm{Co}+\mathrm{Cr}$ and $\mathrm{Co}+\mathrm{Cr}+\mathrm{Fe}$ generally increase the yield strength and decrease density. The 5-element CoCrFeMnNi alloy has the lowest density in the (CoCrFeMnNi) class of alloys, but the strength is not as high as other alloys in this class. V additions increase strength significantly and decrease density only slightly, while Al additions progressively increase strength and decrease density. The effects of Mo, $\mathrm{Nb}$ and $\mathrm{Si}$ on AlCoCrFeNi are also shown in Fig. 9a. All three elements increase the strength, but only Si decreases the density. 
The increasing strength in the (CoCrFeMnNi) class, as elements are progressively added to $\mathrm{Ni}$, gives an overall trend of increasing ductility, and the CoCrFeMnNi alloy has the highest ductility in this class (Fig. 9b). The origins of this behavior have been discussed elsewhere, and include the introduction of extensive nano-twinning [80]. In all other cases shown in Fig. 9b, additions of $\mathrm{Al}, \mathrm{Mo}, \mathrm{Nb}, \mathrm{Si}$ or $\mathrm{V}$ increase the strength but decrease ductility. In each of these cases, increasing concentrations of $\mathrm{Al}, \mathrm{Mo}, \mathrm{Nb}, \mathrm{Si}$ and $V$ introduce increasing volume fractions of intermetallic phases (see Supplemental Information, [4]). Adding Al transforms the fcc CoCrFeMnNi alloy to bcc+fcc+B2 and then to bcc+B2. Increasing $\mathrm{V}$ in CoCrFeMnNi(V) introduces the $\sigma$ phase (D8b, tP30, CrFe prototype). Increasing Mo in AlCoCrFe(Mo)Ni of Si in AlCoCrFeNi(Si) introduces an IM phase to the bcc or bcc+B2 AlCoCrFeNi alloy. Nb introduces the C14 Laves phase to AlCoCrFe(Nb)Ni.

\section{Future directions for material-property databases development}

A detailed description of the balance of properties exhibited by maraging steels was given earlier in this manuscript to emphasize that a single performance index is inadequate to effectively compare different classes of alloys. Indeed, materials selection involves trade-offs between coupled multiple objectives defining several indices and multiple constraints setting property limits. A robust assessment must compare many properties for a given application over a range of relevant temperatures. The main purpose of the present analysis is not to show that any CCA alloy class is superior to existing, commercial alloys, but rather to identify in which property domains experimental CCAs have already achieved some success, so that future efforts can focus on evaluating other properties requirements for which data are not yet available. Tensile ductility and environmental resistance are the first such comparisons suggested for structural materials [81], and others can include fracture toughness, fatigue performance and creep resistance (for high temperature structural applications). 
By definition, reducing alloy density improves specific properties. The present work visually illustrates this benefit by showing how entire alloy families can provide new design options by filling the density gaps between conventional alloy families. The use of $\mathrm{Al}$ and $\mathrm{Ti}$ as principal alloy elements in $3 \mathrm{~d}$ transition metal and refractory metal CCAs is largely responsible for this shift. More systematic pursuit of the approach to fill density gaps in properties space is suggested as a direction for future work. This is already being pursued not only in 3d transition metal CCAs, but also in refractory metal CCAs [64, 65] and in the family of light metal alloys $[56,57,82]$. Broader efforts in these directions are suggested.

Throughout history, the evolution of materials from the few tens of natural materials used by humans (stone, wood...) to the hundreds of thousands of current engineering materials can be regarded as a process of filling the property space [72]. It is worth noticing that numerous CCAs do not fall inside already populated regions and do fill empty areas of the material landscape, meaning that they exhibit a combination of properties that current materials do not provide. However, innovation in the field of materials also requires the enhancement of their performance indices in order to bring an advantage for the considered applications. The present work emphases that the alloy design concept behind CCAs offers a promising mean to expand the world of materials towards interesting gaps associated with improved properties.

Microstructure and materials properties depend on the way the materials have been processed. There are relatively few CCA studies dedicated to tailoring processing and microstructure in CCAs. Where these considerations have been explored, significant improvements and a strong balance of properties can be achieved, see [83] for a recent example. Additional work to tailor microstructures and properties by thermomechanical processing is recommended. 


\section{CONCLUSION}

In this work we conducted an alloy network analysis of five different families of CCAs: $3 \mathrm{~d}$ transition metal CCAs, refractory metal CCAs, light metal CCAs, CCA brasses and bronzes, and lanthanide CCAs.

The potential of the CCAs as structural materials is evaluated graphically using alloy properties maps and performance indices. $3 \mathrm{~d}$ transition metal CCAs and some of the refractory metal CCAs uniquely fill the gap between commercial titanium alloys and steels or nickel alloys, while light metal CCAs fill the gap between Mg alloys and Ti alloys, providing new materials options for structural applications.

In terms of the room temperature specific yield strength, the best $3 d$ transition metal CCAs exceed all commercial alloys (including steels, stainless steels, $\mathrm{Ti}, \mathrm{Al}, \mathrm{Mg}, \mathrm{Ni}$ and refractory alloys) in uniaxial loading and perform as well as the best Mg alloys in beam bending. Where the maximum use temperature eliminates conventional Mg-based and Al-based alloys, and where cost excludes Ti-based alloys, 3d transition metal CCAs emerge as the most attractive option in uniaxial loading, beam bending and panel bending.

The room temperature specific stiffness of the best $3 \mathrm{~d}$ transition metal CCAs is equivalent to the best commercial alloys in uniaxial loading, is better than steels and commercial $\mathrm{Ni}$ and refractory alloys in beam and panel bending, but is poorer than $\mathrm{Mg}, \mathrm{Al}$ and $\mathrm{Ti}$ alloys in bending modes.

The room temperature specific yield strength and stiffness of refractory CCAs do not compete with commercial alloys for any of the three loading conditions considered here. However, temperature dependent yield strength - density charts show that refractory CCAs out-perform commercial Ni alloys and $3 \mathrm{~d}$ transition metal CCAs at $800^{\circ} \mathrm{C}$ and $1000^{\circ} \mathrm{C}$, highlighting their potential interest.

The effect of Al on the mechanical properties and phases of $3 \mathrm{~d}$ transition metal CCAs is illustrated using composition trajectories. Increasing Al increases strength while decreasing density and ductility while transforming single-phase $F C C$ microstructures to duplex $F C C+B C C$ or $F C C+B 2$ microstructures. The 
influence of other elements ( $\mathrm{Mo}, \mathrm{Nb}, \mathrm{Si}, \mathrm{Ti}, \mathrm{V}$ ) are also illustrated. The best CCAs have microstructures that are likely to contain significant amounts of one or more intermetallic phases.

The graphical approach used here shows that the conventional alloying strategy of small elemental additions to a base element improves the room temperature specific yield strength by increasing strength at a relatively constant density. However, increasing the number of principal elements, $N$, has a different effect on the room temperature specific yield strength of CCAs. The overall yield strength increases with increasing $N$, while the density range shrinks from a broad span of roughly $500-20000 \mathrm{~kg}$ $\mathrm{m}^{-3}$ at $N=1$ to a relatively narrow range of $6000-9000 \mathrm{~kg} \mathrm{~m}^{-3}$ at $N \geq 6$.

The present work gives a visual approach that identifies the most attractive alloys for structural applications, and these results are recommended as an aid to focus future studies on the most promising alloys.

\section{ACKNOWLEDGEMENTS}

SG would like to acknowledge DGA (Direction Générale de I'Armement) for support through the ERE program (ERE 201560 0013). The authors thank Adam Pilchak for the support provided for this work. SG thanks Raghavan Srinivasan for the arrangements that were made to host him at Wright State University. Work by ONS was supported through the Air Force onsite contract No. FA8650-15-D-5230 managed by UES, Inc. We thank M. Ashby for providing helpful comments.

\section{REFERENCES}

[1] J.-W. Yeh, S.-K. Chen, S.-J. Lin, J.-Y. Gan, T.-S. Chin, T.-T. Shun, C.-H. Tsau, S.-Y. Chang. Nanostructured high-entropy alloys with multiple principal elements: Novel alloy design concepts and outcomes, Adv. Eng. Mat. 6 (2004) 299-303. 
[2] B. Cantor, I.T.H. Chang, P. Knight, A.J.B. Vincent. Microstructural development in equiatomic multicomponent alloys, Mater. Sci. Eng. A 375-377 (2004) 213-218.

[3] J.-W. Yeh, S.-K. Chen, J.-W. Gan, S.-J. Lin, T.-S. Chin, T.-T.Shun, C.-H. Tsau, S.-Y. Chang. Formation of simple crystal structures in Cu-Co-Ni-Cr-Al-Fe-Ti-V alloys with multiprincipal metallic elements, Metall. Mater. Trans. A 35A (2004) 2533-2536.

[4] D.B. Miracle, O.N. Senkov. A critical review of high entropy alloys and related concepts, Acta Mater. 122 (2017) 448-511.

[5] W.P. Huhn, M. Widom. Prediction of A2 to B2 phase transition in the high-entropy alloy Mo-NbTa-W, JOM 65 (2013) 1772-1779.

[6] K.C. Hsieh, C.F. Yu, W.T. Hsieh, W.R. Chiang, J.S. Ku, J.H. Lai, C.P. Tu, C.C. Yang. The microstructure and phase equilibrium of new high performance high-entropy alloys, Journal of Alloys and Compounds 483 (2009) 209-212.

[7] J. Chen, P. Niu, Y. Liu, Y. Lu, X. Wang, Y. Peng, J. Liu. Effect of Zr content on microstructure and mechanical properties of AlCoCrFeNi high entropy alloy, Materials and Design 94 (2016) 39-44.

[8] O.N. Senkov, D. Isheim, D.N. Seidman, A.L. Pilchak. Development of a Refractory High Entropy Superalloy, Entropy 18 (2016) 102.

[9] A. Manzoni, H. Daoud, R. Volkl, U. Glatzel, N. Wanderka. Phase separation in equiatomic AlCoCrFeNi high-entropy alloy, Ultramicroscopy 132 (2013) 212-215.

[10] M.R. Chen, S.J. Lin, J.W. Yeh, S.K. Chen, Y.S. Huang, M.H. Chuang. Effect of vanadium addition on the microstructure, hardness, and wear resistance of Al0.5CoCrCuFeNi high-entropy alloy, Metall. Mater. Trans. A 37A (2006) 1363-1369. 
[11] J.Y. He, H. Wang, H.L. Huang, X.D. Xu, M.W. Chen, Y. Wu, X.J. Liu, T.G. Nieh, K. An, Z.P. Lu. A precipitation-hardened high-entropy alloy with outstanding tensile properties, Acta Materialia 102 (2016) 187-196.

[12] E.J. Pickering, R. Munoz-Moreno, H.J. Stone, N.G. Jones. Precipitation in the equiatomic highentropy alloy CrMnFeCoNi, Scripta Materialia 113 (2016) 106-109.

[13] K.G. Pradeep, C.C. Tasan, M.J. Yao, Y. Deng, H. Springer, D. Raabe. Non-equiatomic high entropy alloys: Approach towards rapid alloy screening and property-oriented design, Mater. Sci. Eng. A 648 (2015) 183-192.

[14] E. Gamsjaeger, Y. Liu, M. Rester, P. Puschnig, C. Draxl, H. Clemens, G. Dehm, F.D. Fischer. Diffusive and massive phase transformations in Ti-Al-Nb alloys - Modelling and experiments, Intermetallics 38 (2013) 126-138, Scripta Materialia 127 (2017) 186-190.

[15] D. Choudhuri, B. Gwalani, S. Gorsse, C.V. Mikler, R.V. Ramanujan, M.A. Gibson, R. Banerjee, Change in the primary solidification phase from fcc to bcc-based B2 in high entropy or complex concentrated alloys

[16] M.-H. Chuang, M.-H. Tsai, W.-R. Wang, S.-J. Lin, J.-W. Yeh, Microstructure and wear behavior of AlxCo1.5CrFeNi1.5Tiy high-entropy alloys, Acta Mater. 59 (2011) 6308-6317.

[17] J.-W. Yeh, Recent Progress in High-entropy Alloys, Annales de Chimie - Science des Materiaux 31 (2006) 633-648.

[18] Chung-Jin Tong et al., Microstructure Characterization of AlxCoCrCuFeNi High-Entropy Alloy System with Multiprincipal Elements, Metall. Mater. Trans. A 36 (2005) 881.

[19] C.-J. Tong, M.-R. Chen, S.-K. Chen, J.-W. Yeh, T.-T. Shun, S.-J. Lin, and S.-Y. Chang, Mechanical Performance of the AlxCoCrCuFeNi High-Entropy Alloy System with Multiprincipal Elements, Metall. Mater. Trans. A 26 (2005) 1263. 
[20] J.Y. He, W.H. Liu, H. Wang, Y. Wu, X.J. Liu, T.G. Nieh, Z.P. Lu, Effects of Al addition on structural evolution and tensile properties of the FeCoNiCrMn high-entropy alloy system, Acta Mater. 62 (2014) 105-113.

[21] C.-Y. Hsu, C.-C. Juan, T.-S. Sheu, S.-K. Chen, and J.-W. Yeh, Effect of Aluminum Content on Microstructure and Mechanical Properties of AlxCoCrFeMo0.5Ni High-Entropy Alloys, JOM 65 (2013) 1840-1847.

[22] Y.-F. Kao, T.-J. Chen, S.-K. Chen, J.-W. Yeh, Microstructure and mechanical property of as-cast, homogenized, and -deformed AlxCoCrFeNi (x=0-2) high-entropy alloys, J. Alloys Compds 488 (2009) 5764.

[23] C. Li, J.C. Li, M. Zhao, Q. Jiang, Effect of alloying elements on microstructure and properties of multiprincipal elements high-entropy alloys, J. Alloys Compds 475 (2009) 752-757.

[24] S.G. Ma, Y. Zhang, Effect of Nb addition on the microstructure and properties of AlCoCrFeNi highentropy alloy, Mater. Sci. Eng. A 532 (2012) 480- 486.

[25] J.M. Zhu, H.M. Fu, H.F. Zhang, A.M. Wang, H. Li, Z.Q. Hu, Microstructure and compressive properties of multiprincipal component AlCoCrFeNiCx alloys, J. Alloys Compds 509 (2011) 3476-3480.

[26] J.M. Zhu, H.M. Fu, H.F. Zhang, A.M. Wang, H. Li, Z.Q. Hu, Synthesis and properties of multiprincipal component AlCoCrFeNiSix alloys, Materials Science and Engineering A 527 (2010) 72107214.

[27] J.M. Zhu, H.M. Fu, H.F. Zhang, A.M. Wang, H. Li, Z.Q. Hua, Microstructures and compressive properties of multicomponent AlCoCrFeNiMox alloys, Materials Science and Engineering A 527 (2010) 6975-6979.

[28] Y.P. Wang, B.S. Li, M.X. Ren, C. Yang, H.Z. Fu, Microstructure and compressive properties of AlCrFeCoNi high entropy alloy, Materials Science and Engineering A 491 (2008) 154-158. 

Microstructure and mechanical properties of CoCrFeNiTiAlx high-entropy alloys, Materials Science and Engineering A 508 (2009) 214-219.

[30] T.T. Zuo, R.B. Li, X.J. Ren, Y. Zhang, Effects of Al and Si addition on the structure and properties of CoFeNi equal atomic ratio alloy, Journal of Magnetism and Magnetic Materials 371 (2014) 60-68.

[31] S. Guo, C. Ng, J. Lu, and C. T. Liu, Effect of valence electron concentration on stability of fcc or bcc phase in high entropy alloys, Journal of Applied Physics 109 (2011) 103505-5.

[32] S.T. Chen et al., Microstructure and properties of age-hardenable AlxCrFe1.5MnNi0.5 alloys, Materials Science and Engineering A 527 (2010) 5818-5825.

[33] F.J. Wang, Y. Zhang, G.L. Chen, Atomic packing efficiency and phase transition in a high entropy alloy, Journal of Alloys and Compounds 478 (2009) 321-324.

[34] Z. Wu, H. Bei, G.M. Pharr, E.P. George, Temperature dependence of the mechanical properties of equiatomic solid solution alloys with face-centered cubic crystal structures, Acta Mater. 81 (2014) 428441.

[35] C.-Y. Hsu, W.-R. Wang, W.-Y. Tang, S.-K. Chen and J.-W. Yeh, Microstructure and Mechanical Properties of New AlCoxCrFeMo0.5Ni High-Entropy Alloys, Advanced Engineering Materials 12 (2010) 4449.

[36] B.S. Murty, Jien-Wei Yeh, S. Ranganathan, High Entropy Alloys, $1^{\circ}$ edition, ButterworthHeinemann, ISBN 9780128002513.

[37] C.P. Lee, Y.Y. Chen, C.Y. Hsu, J.-W. Yeh, H.C. Shih, The effect of boron on the corrosion resistance of the high entropy alloys Al0.5CoCrCuFeNiBx, J. Electrochem. Soc. 154 (2007) C424-C430.

[38] M.-R. Chen, S.-J. Lin, J.-W. Yeh, S.-K. Chen, Y.-S. Huang, C.-P. Tu, Microstructure and Properties of Al0:5CoCrCuFeNiTix (x = 0-2.0) High-Entropy Alloys, Materials Transactions 47 (2006) 1395-1401. 

the Microstructure, Hardness, and Wear Resistance of Al0.5CoCrCuFeNi High-Entropy Alloy, Metall. Mater. Trans. A 37 (2006) 1363-1369.

[40] S. Guo, C.T. Liu, Phase stability in high entropy alloys: Formation of solid-solution phase or amorphous phase, Materials International 21 (2011) 433-446.

[41] C.Y. Hsu, T.S. Sheu, J.W. Yeh, S.K. Chen, Effect of iron content on wear behavior of AlCoCrFexMo0.5Ni high-entropy alloys, Wear 268 (2010) 653-659.

[42] B.S. Li, Y.P. Wang, M.X. Ren, C. Yang, H.Z. Fu, Effects of Mn, Ti and V on the microstructure and properties of AlCrFeCoNiCu high entropy alloy, Materials Science and Engineering A 498 (2008) 482-489.

[43] Z. Hu, Y. Zhan, G. Zhang, J. She, C. Li, Effect of rare earth Y addition on the microstructure and mechanical properties of high entropy AlCoCrCuNiTi alloys, Materials and Design 31 (2010) 1599-1605.

[44] C.-C. Juan, C.-Y. Hsu, C.-W. Tsai, W.-R. Wang, T.-S. Sheu, J.-W. Yeh, S.-K. Chen, On microstructure and mechanical performance of AlCoCrFeMo0.5Nix high-entropy alloys, Intermetallics 32 (2013) 401407.

[45] Y.X. Zhuang, W.J. Liu, Z.Y. Chen, H.D. Xue, J.C. He, Effect of elemental interaction on microstructure and mechanical properties of FeCoNiCuAl alloys, Materials Science \& Engineering A 556 (2012) 395-399.

[46] P. Jinhong, P. Ye, Z. Hui, Z. Lu, Microstructure and properties of AlCrFeCuNix $(0.6=x=1.4)$ highentropy alloys, Materials Science and Engineering A 534 (2012) 228-233.

[47] Y. Dong, Y. Lu, J. Kong, J. Zhang, T. Li, Microstructure and mechanical properties of multicomponent AlCrFeNiMox high-entropy alloys, Journal of Alloys and Compounds 573 (2013) 96-101.

[48] É. Fazakas, V. Zadorozhnyy, D.V. Louzguine-Luzgin, Effect of iron content on the structure and mechanical properties of Al25Ti25Ni25Cu25 and (AlTi)60-xNi20Cu20Fex ( $x=15,20)$ high-entropy alloys, Appl. Surf. Sci. 358 (2015) 549-555. 
[49] X.F. Wang, Y. Zhang, Y. Qiao, G.L. Chen, Novel microstructure and properties of multicomponent CoCrCuFeNiTix alloys, Intermetallics 15 (2007) 357-362.

[50] W.H. Liu, J.Y. He, H.L. Huang, H. Wang, Z.P. Lu, C.T. Liu, Effects of Nb additions on the microstructure and mechanical property of CoCrFeNi high-entropy alloys, Intermetallics 60 (2015) 1-8.

[51] N.D. Stepanov, D.G. Shaysultanov, G.A. Salishchev, M.A. Tikhonovsky, E.E. Oleynik, A.S. Tortika, O.N. Senkov, Effect of v content on microstructure and mechanical properties of the CoCrFeMnNiVx high entropy alloys, Journal of Alloys and Compounds 628 (2015) 170-85.

[52] L. Liu, J.B. Zhu, L. Li, J.C. Li, Q. Jiang, Microstructure and tensile properties of FeMnNiCuCoSnx high entropy alloys, Materials and Design 44 (2013) 223-27.

[53] L. Liu, J.B. Zhu, C. Zhang, J.C. Li, Q. Jiang, Microstructure and the properties of FeCoCuNiSnx high entropy alloys, Mater. Sci. Eng. A 548 (2012) 64-68.

[54] L. Jiang, Z.Q. Cao, J.C. Jie, J.J. Zhang, Y.P. Lu, T.M. Wang, T.J. Li, Effect of Mo and Ni elements on microstructure evolution and mechanical properties of the CoFeNixVMoy high entropy alloys, Journal of Alloys and Compounds 649 (2015) 585-590.

[55] K.J. Laws, C. Crosby, A. Sridhar, P. Conway, L.S. Koloadin, M. Zhao, S. Aron-Dine, L. C. Bassman, High entropy brasses and bronzes e Microstructure, phase evolution and properties, Journal of Alloys and Compounds 650 (2015) 949-961.

[56] X. Yang, S.Y. Chen, J.D. Cotton and Y. Zhang, Phase Stability of Low-Density, Multiprincipal Component Alloys Containing Aluminum, Magnesium, and Lithium, JOM 66(10) (2014) 2009-2020.

[57] K.M. Youssef, A.J. Zaddach, C. Niu, D.L. Irving, C.C. Koch, A Novel Low-Density, High-Hardness, High entropy Alloy with Close-packed Single-phase Nanocrystalline Structures, Mater. Res. Lett. 3 (2015) 95-99.

[58] O.N. Senkov, C.F. Woodward, Microstructure and properties of a refractory NbCrMo0.5Ta0.5TiZr alloy, Materials Science and Engineering A 529 (2011) 311-320. 
[59] O.N. Senkov, V.Senkova, D.B.Miracle, C.Woodward, Mechanical properties of low-density, refractory multi-principal element alloys of the $\mathrm{Cr}-\mathrm{Nb}-\mathrm{Ti}-\mathrm{V}-\mathrm{Zr}$ system, Materials Science \& Engineering A 565(2013) 51-62.

[60] O. N. Senkov, J. M. Scott, S. V. Senkova, F. Meisenkothen, D. B. Miracle, C. F. Woodward, Microstructure and elevated temperature properties of a refractory TaNbHfZrTi alloy, J. Mater. Sci. 47 (2012) 4062-4074.

[61] O.N. Senkov, J.M. Scott, S.V. Senkova, D.B. Miracle, C.F. Woodward, Microstructure and room temperature properties of a high-entropy TaNbHfZrTi alloy, Journal of Alloys and Compounds 509 (2011) 6043-6048.

[62] O.N. Senkov, G.B. Wilks, J.M. Scott, D.B. Miracle, Mechanical properties of Nb25Mo25Ta25W25 and V20Nb20Mo20Ta20W20 refractory high entropy alloys, Intermetallics 19 (2011) 698-706.

[63] O.N. Senkov, G.B. Wilks, D.B. Miracle, C.P. Chuang, P.K. Liaw, Refractory high-entropy alloys, Intermetallics 18 (2010) 1758-1765.

[64] O.N. Senkov, C. Woodward, D.B. Miracle, Microstructure and properties of Aluminum-containing refractory high entropy alloys, JOM 66 (10) (2014) 2030-2042.

[65] O.N. Senkov, S.V. Senkova, C. Woodward, D.B. Miracle, Low-density, refractory multi-principal element alloys of the $\mathrm{Cr}-\mathrm{Nb}-\mathrm{Ti}-\mathrm{V}-\mathrm{Zr}$ system: Microstructure and phase analysis, Acta Materialia 61 (2013) 1545-1557.

[66] N.D. Stepanov, D.G. Shaysultanov, G.A. Salishchev, M.A. Tikhonovsky, Structure and mechanical properties of a light-weight AINbTiV high entropy alloy, Materials Letters142 (2015) 153-155

[67] X. Yang, Y. Zhang and P.K. Liaw, Microstructure and Compressive Properties of NbTiVTaAlx High Entropy Alloys, Procedia Engineering 36 (2012) 292-298. 

high-entropy alloy with excellent structural stability and tensile properties, Materials Letters 130 (2014) 277-280.

[69] J.-W. Yeh, S.-K. Chen, S.-J. Lin, J.-Y. Gan, T.-S. Chin, T.-T.Shun, C.-H. Tsau, S.-Y. Chang, Nanostructured high-entropy alloys with multiple principal elements: Novel alloy design concepts and outcomes, Adv. Eng. Mat. 6 (2004) 299-303.

[70] Y. Zhang, X. Yang, and P. K. Liaw, Alloy Design and Properties Optimization of High-Entropy Alloys, JOM 64 (7) (2012) 830-838.

[71] CES EduPack 2016, Granta Design Ltd. Cambridge UK (www.grantadesign.com/education)

[72] M.F. Ashby, (2017), Materials selection in mechanical design", $5^{\text {rd }}$ edition, Butterworth Heinemann, Oxford, UK., ISBN 9780081005996/

[73] M. E. J. Newman and M. Girvan, Finding and evaluating community structure in networks. Phys. Rev. E 69 (2004) 026113.

[74] M. Bastian, S. Heymann, and M. Jacomy, "Gephi: an open source software for exploring and manipulating networks," in International AAAI Conference on Weblogs and Social Media. Association for the Advancement of Artificial Intelligence, 2009.

[75] O.N. Senkov, D.B. Miracle, V. Keppens, P.K. Liaw. Development and Characterization of LowDensity Ca-Based Bulk Metallic Glasses: An Overview, Metall. Mater. Trans. 39A (2008) 1888-1900.

[76] D.B. Miracle. Overview No. 104: The physical and mechanical properties of NiAl, Acta Metall. Mater. 41 (1993) 649-684.

[77] K. Vedula. FeAl and Fe3Al. in: Westbrook JH, Fleischer RL, (Eds.). Intermetallic Compounds: Principles and Practice, vol. 2 - Practice. John Wiley \& Sons, Ltd., West Sussex, England, 1995. pp. 199209. 
[78] O.N. Senkov, J.W. Miller, D.B. Miracle, C. Woodward. Accelerated exploration of multi-principal element alloys with solid solution phases, Nature Communications 6 (2015) 6529.

[79] O.N. Senkov, J.D. Miller, D.B. Miracle, C. Woodward. Accelerated exploration of multi-principal element alloys for structural applications, Calphad: Computer Coupling of Phase Diagrams and Thermochemistry 50 (2015) 32-48.

[80] B. Gludovatz, A. Hohenwarter, D. Catoor, E.H. Chang, E.P. George, R.O. Ritchie. A fractureresistant high-entropy alloy for cryogenic applications, Science 345 (2014) 1153-1158.

[81] D.B. Miracle, B. Majumdar, K. Wertz, S. Gorsse. New strategies and tests to accelerate discovery and development of multi-principal element structural alloys, Scripta Mater. 127 (2017) 195-200.

[82] S. Gorsse, S. Couillaud, E. Gaudin, J.-L. Bobet, Physical properties of the multifunctional Mg80Ni10Gd10 alloy, Materials Science \& Engineering A 687 (2017), DOI: 10.1016/j.msea.2017.01.085.

[83] Z. Li, K.G. Pradeep, Y. Deng, D. Raabe, C.C. Tasan. Metastable high-entropy dual-phase alloys overcome the strength-ductility trade-off, Nature 534 (2016) 227-230. 